\title{
Level of Maternal Satisfaction and its Determinants at Health Facilities in Mizan-Aman Town, Ethiopia: Cross Sectional Study
}

\author{
Teklemariam Ergat Yarinbab ${ }^{1^{*}}$, Wasihun Adraro Ambo ${ }^{2}$, Tariku Regea ${ }^{2}$ and Addisu G/Mariam ${ }^{2}$
}

${ }^{1}$ Department of Public Health, College of Health Science, Mizan-Tepi University, Ethiopia

${ }^{2}$ Department of Public Health, Mizan-Aman College of Health Science, Ethiopia

*Corresponding author: Teklemariam Ergat Yarinbab, Department of Public Health, College of Health Science, Mizan-Tepi University, Ethiopia

\begin{abstract}
Background: Maternal satisfaction on institutional delivery service is the most frequently reported indicator in the evaluation of the quality of maternity services. While increasing service availability and maintaining acceptable quality standards, it is important to assess maternal satisfaction with care in order to make it more responsive and culturally acceptable, ultimately leading to enhanced utilization and improved outcomes. Maternal satisfaction determines the level of institutional delivery service utilization. Therefore, the aim of this study was to assess the determinants of maternal satisfaction on delivery service among mothers who gave birth at health facilities in MizanAman Town, Ethiopia.

Methods: Cross-sectional study was conducted in MizanAman Town, Ethiopia. A systematic sampling technique was used. Pre-tested structured questionnaires were used to collect the data. Both bivariate and multivariate data analysis was conducted by SPSS version 20 .

Result: Level of maternal satisfaction was $30.4 \%$. Antenatal care visit $(A O R=6.48,95 \% \mathrm{Cl}=1.01,41.68)$, delivery at health center $(A O R=2.14,95 \% \mathrm{Cl}=1.15,3.99)$ and stay at labor less than six-hours $(\mathrm{AOR}=2.83,95 \% \mathrm{Cl}=1.34,5.96)$ were significantly associated with maternal satisfaction.

Conclusion: Antenatal care visit, health center delivery and less prolonged labor were major determinants of maternal satisfaction.
\end{abstract}

\section{Keywords}

Maternal satisfaction, Institutional delivery service, MizanAman Town, Ethiopia

\section{List of Abbreviations}

AOR: Adjusted Odds Ratio; ANC: Antenatal Care; SPSS: Statistical Package for Social Sciences

\section{Introduction}

Every day, approximately 830 women die from preventable causes related to pregnancy and childbirth. Of these, $99 \%$ of all maternal deaths occur in developing countries [1]. Owing to considerable gaps in services, developing countries emphasize on increasing service availability and maintaining acceptable quality standards [2]. Understanding maternal perception of care and satisfaction with services is important in this regard, as perceived quality is a key determinant of service utilization $[3,4]$.

Users who perceive the quality of care in a health center to be good, are more likely to visit it again, thereby increasing demand for the service $[5,6]$. Service utilization and positive maternal and neonatal outcomes can be significantly enhanced by improving quality of facility deliveries and making them more acceptable to women [7].

User satisfaction is considered 'patient's judgment on the quality and goodness of care [8]. Patient satisfaction is thus indispensible to quality improvement with regard to design and management of health care systems [4].

Maternal satisfaction has often been defined using theoretical models of patient satisfaction [9]. But there is consensus that it is a multidimensional concept, influenced by a variety of factors $[9,10]$. It is also defined as positive evaluation of distinct dimensions of childbirth [11]. 
Evidence on maternal satisfaction with the quality of maternal care helps to determine other aspects of care that need strengthening in developing country contexts to support long-term demand, generate significant changes in maternal care-seeking behavior, and identify barriers that can and should be removed. Therefore, the aim of this study was to assess the determinants of maternal satisfaction on delivery service among mothers who gave birth at health facilities in MizanAman Town, Ethiopia.

\section{Methods and Materials}

Study area: The study was conducted in Mizan Aman town from May 01-30/2018. The town was an administrative city of Bench Maji Zone (found in Southern Nations, Nationalities and Peoples region). It is located $583 \mathrm{KMs}$ southwest of Addis Ababa. The town had an estimated total population of 48,934 among which 51\% were females (2015 National Census). The town was divided in to 5 kebeles (the smallest administrative units). It had one Teaching Hospital, One Public Health Center and Four Health Posts. There were 21 private clinics in the town.

Study design: Cross sectional study was conducted.

\section{Inclusion \& exclusion criteria}

Inclusion Criteria: Women who gave birth at public health institutions in the past 12 months were included in the study.

Exclusion Criteria: Women who were not willing to answer the questionnaires or critically ill at the time of data collection were excluded from the study.

\section{Sample size determination}

The sample size was calculated by using a single population proportion formula. The total population was 48,934 of which $49 \%$ were females. Considered assumptions were: $P=79.1 \%[12]$, margin of error to be $5 \%(\mathbf{d}=0.05)$ and $Z \alpha / 2=1.96$. The final sample size with $10 \%$ non-response rate was 280 .

\section{Sampling technique}

The card number and the respective addresses of mothers who gave birth in health institutions within the last 12 months were obtained from delivery registration books. Then health extension workers were used to get the home of study subjects. Then systematic random sampling technique was used. The total number of institutional delivery from the town was 1246 whereas the sample size considered for this study was 280 . This sample size was allocated proportionally to each of the five kebeles based on their delivery record, i.e. Edget (41), Addis Ketema (63), Hibret (88), Shesheqa (46) and Kometa (42).

\section{Data collection tool and procedure}

Data was collected by face to face interview using structured and pre-tested questionnaires. It was prepared in English and then translated in to Amharic language (official language of the region) and retranslated to English to insure correct translation prior to the start of the fieldwork. Five health workers who were fluent in the local languages were used to collect the data.

\section{Data quality control}

Pre-test was done on $5 \%$ of the questionnaires in Kite Town/Kebele (i.e. a small town in the neighboring District). Orientation was given for the data collectors. Supervisors checked the completeness of data on daily basis (Appendix).

\section{Data processing and analysis}

Data analysis was conducted by using SPSS Version 20.0. Bivariate and Multivariate logistic regression analysis was conducted. P-Value $\leq 0.05$ was considered to declare statistically significant variables.

\section{Operational definition}

Satisfied: If $75 \%$ of the study mothers/respondents/ response is above fairly satisfied.

Dissatisfied: If above $25 \%$ of the respondents reported unsatisfied.

\section{Result}

\section{Socio-demographic profile of respondents}

A total of 280 women participated in the study with a response rate of $100 \%$. The mean age of study participants was $25.7( \pm 5.4)$ years. One hundred forty $(50.0 \%)$ attended secondary school (Table 1 ).

\section{Obstetric history of respondents}

About 117 (41.8\%) of the study participants were primiparous. Two hundred sixty seven $(95.36 \%)$ had reported at least one ANC follow up. One hundred seventy five $(62.5 \%)$ of the women who participated in the study reported to gave birth in Hospital whereas 105 (37.5\%) of them reported to gave birth in Health Center (Table 2).

\section{Maternal satisfaction}

The overall delivery service satisfaction of study participants was $30.4 \%$. One hundred forty $(50 \%)$ of the study participants reported that they were satisfied with the delivery services at the health facility. One hundred sixty four (58.57\%) of study participants also reported that they were satisfied by intermediate and final outcomes of the delivery service.

Around $54 \%$ of satisfied study participants were those whose place of delivery was at Health centers. The age of majority satisfied study participants $(65.95 \%)$ are in the range of $17-25$ years old. More than half (51.8\%) of satisfied participants educational status was high 
Table 1: Socio-demographic profile of the study participants, Mizan Aman, Ethiopia, May 2018.

\begin{tabular}{|c|c|c|}
\hline Variables & Frequency & Percent \\
\hline \multicolumn{3}{|l|}{ Age } \\
\hline $15-25$ & 151 & 53.9 \\
\hline $26-34$ & 112 & 40.0 \\
\hline$\geq 35$ & 17 & 6.1 \\
\hline \multicolumn{3}{|l|}{ Marital status } \\
\hline Unmarried & 20 & 7.2 \\
\hline Married & 260 & 92.8 \\
\hline \multicolumn{3}{|l|}{ Religion } \\
\hline Orthodox & 127 & 45.4 \\
\hline Muslim & 44 & 15.7 \\
\hline Protestant & 109 & 38.9 \\
\hline \multicolumn{3}{|l|}{ Ethnicity } \\
\hline Bench & 86 & 30.8 \\
\hline Kaffa & 62 & 22.1 \\
\hline Amhara & 51 & 18.2 \\
\hline Others & 81 & 28.9 \\
\hline \multicolumn{3}{|c|}{ Maternal educational status } \\
\hline Unable to write and read & 6 & 2.1 \\
\hline Elementary & 99 & 35.3 \\
\hline Secondary & 140 & 50.0 \\
\hline College and Above & 35 & 12.5 \\
\hline \multicolumn{3}{|c|}{ Paternal educational status } \\
\hline Elementary \& below & 130 & 64.9 \\
\hline Secondary & 76 & 27.3 \\
\hline College and Above & 74 & 4.8 \\
\hline \multicolumn{3}{|l|}{ Maternal occupation } \\
\hline Government employee & 50 & 17.8 \\
\hline Merchant & 50 & 17.8 \\
\hline House wife & 160 & 57.1 \\
\hline Student & 20 & 7.1 \\
\hline \multicolumn{3}{|c|}{ Household monthly income (USD) } \\
\hline$<50$ USD & 133 & 47.5 \\
\hline$\geq 50$ USD & 147 & 52.5 \\
\hline
\end{tabular}

school and above. Fifty five around (64.7\%) of satisfied participants were either house wives or students. Forty one $(46.6 \%)$ mothers who stayed 6 to 12 hours on labour in the health institutions were satisfied.

\section{Factors associated with maternal satisfaction}

The multivariate logistic regression analysis showed that antenatal care visit, health center delivery and less prolonged labor were major determinants of maternal satisfaction.

The study further revealed that those women who did not attend ANC service during their pregnancy were six times $(A O R=6.48,95 \% \mathrm{Cl}=1.01,41.68)$ more likely to be satisfied as compared to that of mothers who reported four or more times ANC follow up. Besides, mothers who gave birth in the health center were two times $(A O R=2.14,95 \% \mathrm{Cl}=1.15,3.99)$ more likely to be satisfied compared to mothers who gave birth in the hospital.

The study also showed those mothers who have stayed on labour for 6-12 hours were nearly three times $(A O R=2.83,95 \% \mathrm{Cl}=1.34,5.96)$ more satisfied on
Table 2: Obstetric history of study participants, Mizan Aman, Ethiopia, May 2018.

\begin{tabular}{|c|c|c|}
\hline Variables & Frequency & Percent \\
\hline \multicolumn{3}{|c|}{ Was the pregnancy wanted? } \\
\hline Yes & 222 & 79.3 \\
\hline No & 58 & 20.7 \\
\hline \multicolumn{3}{|l|}{ Parity } \\
\hline One & 117 & 41.8 \\
\hline Two - Four & 143 & 51.1 \\
\hline Five and more & 20 & 7.1 \\
\hline \multicolumn{3}{|c|}{ Duration of labour in the $\mathrm{HI}$} \\
\hline 6 hours & 107 & 38.2 \\
\hline $6-12$ Hours & 88 & 31.4 \\
\hline $12-24 \mathrm{Hrs}$ & 69 & 24.6 \\
\hline More than $24 \mathrm{Hrs}$ & 16 & 5.8 \\
\hline \multicolumn{3}{|c|}{ Facility for delivery } \\
\hline Health Center & 105 & 37.5 \\
\hline Hospital & 175 & 62.5 \\
\hline \multicolumn{3}{|c|}{ Who decided to go to HF } \\
\hline My self & 87 & 31.1 \\
\hline Family or HEW & 193 & 68.9 \\
\hline \multicolumn{3}{|l|}{ Mode of delivery } \\
\hline SVD & 237 & 84.6 \\
\hline Assisted delivery & 21 & 7.5 \\
\hline Cesarean section & 22 & 7.9 \\
\hline \multicolumn{3}{|c|}{ Reason for choosing the facility } \\
\hline Planned & 255 & 91.1 \\
\hline Referral & 25 & 8.9 \\
\hline
\end{tabular}

delivery care services than those mothers who stayed on labour for less than 6 hours (Table 3).

\section{Discussion}

The overall maternal satisfaction of the study participants was $30.4 \%$. This finding was lower than the study finding from Gamo Gofa Zone, Ethiopia, which was $79 \%$ [12]. The possible reason may be the differences in the quality of care in both settings but it needs further investigation as these issues were not addressed in the study.

The study further revealed that those women who did not attend ANC service during their pregnancy were six times more likely to be satisfied as compared to that of mothers who reported four or more times ANC follow up. The finding was similar with a study finding in BahirDar City at Felege Hiwot Referral Hospital, Ethiopia [13], which showed women who did not attend ANC were 3 times more likely to be satisfied with childbirth care services compared to women those attended ANC follow up. This similarity might be due to the similarities in the socio-cultural status of the population and the similarity of the health care services in the health institutions.

Besides, mothers who gave birth in the health center were two times more likely to be satisfied compared to mothers who gave birth in the hospital. The study also showed those mothers who have stayed on labour for 6-12 hours were nearly three times more satisfied on delivery care services than those mothers who stayed on labour for less than 6 hours. It is clear that maternal 
Table 3: Factors associated with maternal satisfaction, Mizan Aman, May 2018.

\begin{tabular}{|c|c|c|c|c|c|}
\hline \multirow[t]{2}{*}{ Variable } & & \multicolumn{2}{|c|}{ Satisfied on delivery service } & \multirow[t]{2}{*}{ COR $(95 \% \mathrm{Cl})$} & \multirow[t]{2}{*}{ AOR (95\% Cl) } \\
\hline & & No (\%) & Yes (\%) & & \\
\hline \multirow[t]{3}{*}{ Age } & $17-25$ & $95(62.9)$ & $56(37.1)$ & 1 & 1 \\
\hline & $26-34$ & $84(75)$ & $28(25)$ & $0.56(0.32,0.97)$ & $0.71(0.37,1.37)$ \\
\hline & $>35$ & $16(94.1)$ & $1(5.9)$ & $0.10(0.01,0.82)$ & $0.16(0.01,1.34)$ \\
\hline \multirow[t]{2}{*}{ Marital Status } & Unmarried & $11(55)$ & $9(45)$ & 1 & 1 \\
\hline & Married & $184(70.8)$ & $76(29.2)$ & $0.5(0.20,1.26)$ & $1.98(0.47,8.26)$ \\
\hline \multirow[t]{4}{*}{ Educational status } & Unable to Read \& Write & $29(80.6)$ & $7(19.4)$ & $0.45(0.15,1.27)$ & $1.1(0.21,5.19)$ \\
\hline & Primary & $89(72.4)$ & $34(17.6)$ & $0.71(0.33,1.49)$ & $1.85(0.46,7.33)$ \\
\hline & Secondary & $49(62.8)$ & $29(37.2)$ & $1.1(0.5,2.4)$ & $1.86(0.46,6.52)$ \\
\hline & Tertiary & $28(65.1)$ & $15(34.9)$ & 1 & 1 \\
\hline \multirow[t]{4}{*}{ Occupation } & House Wife & $171(79.9)$ & $43(20.1)$ & $0.59(0.30,1.17)$ & $0.67(0.20,2.16)$ \\
\hline & Gov employee & $31(62)$ & $19(38)$ & 1 & 1 \\
\hline & Merchant & $39(78)$ & $11(22)$ & $0.46(0.19,1.10)$ & $0.31(0.09,1.17)$ \\
\hline & Student & $8(40)$ & $12(60)$ & $2.44(0.84,7.1)$ & $2.2(0.52,9.31)$ \\
\hline \multirow{5}{*}{ ANC visit, } & None & $5(38.5)$ & $8(61.5)$ & $3.8(1.2,12.1)$ & $6.5(1.01,41.68)$ \\
\hline & Once & $9(81.8)$ & $2(18.2)$ & $0.53(0.11,2.51)$ & $0.25(0.04,1.48)$ \\
\hline & Twice & $26(76.5)$ & $8(23.5)$ & $0.73(0.31,1.71)$ & $0.71(0.25,2.03)$ \\
\hline & Three times & $20(66.7)$ & $10(33.3)$ & $1.2(0.52,2.69)$ & $1.4(0.55,3.38)$ \\
\hline & Four times & $135(18.6)$ & $57(81.4)$ & 1 & 1 \\
\hline \multirow[t]{2}{*}{ Decision maker } & My self & $53(60.9)$ & $34(39.1)$ & 1 & 1 \\
\hline & Family & $142(73.6)$ & $51(26.4)$ & $0.56(0.32,0.96)$ & $0.47(0.22,0.99)^{*}$ \\
\hline \multirow[t]{2}{*}{ Type of HI } & Hospital & $136(77.7)$ & $39(22.3)$ & 1 & 1 \\
\hline & Health center & $59(56.1)$ & $46(43.9)$ & $2.72(1.61,4.59)$ & $2.14(1.15,3.99)^{*}$ \\
\hline \multirow{4}{*}{$\begin{array}{l}\text { Duration of labour in } \\
\text { the } \mathrm{HI}\end{array}$} & $6 \mathrm{hrs}$ and less & $81(75.7)$ & $26(24.3)$ & 1 & 1 \\
\hline & $6-12$ hrs & $47(53.4)$ & $41(46.6)$ & $2.72(1.48,4.99)$ & $2.83(1.34,5.96)^{*}$ \\
\hline & $12-24 \mathrm{hrs}$ & $54(78.3)$ & $15(21.7)$ & $0.87(0.42,1.78)$ & $0.98(0.43,2.21)$ \\
\hline & $>24 \mathrm{hrs}$ & $13(81.3)$ & $3(18.7)$ & $0.71(0.19,2.72)$ & $0.51(0.10,2.60)$ \\
\hline
\end{tabular}

Key: ${ }^{*}=$ Significant at p-value < 0.05 on multivariate logistic analysis, HI: Health Institutions; COR: Crude Odds Ratio; AOR: Adjusted Odds Ratio.

satisfaction depends on the care given by the health workers. Hence we can deduce that mothers who stayed in labor for a longer time might have a better exposure to the care given by the health professionals. Therefore, they will be in a better position to judge the services delivered by the health workers. This study finding contradicts with a study finding in DebreMarkos, Ethiopia [14]. The differences in the quality of care given might have contributed to the difference but it needs further investigation.

\section{Conclusion}

The overall level of maternal satisfaction was $30.4 \%$. The mean age of study participants was $25.7( \pm 5.4)$ years. Antenatal care visit, delivery at health center and stay at labor less than six-hours were significantly associated with maternal satisfaction.

\section{Recommendation}

Ethiopian Federal Ministry of Health and Regional Health Bureaus should work hard on the maternal care to improve the maternal satisfaction during delivery. Mizan-Tepi University Teaching Hospital should also work on the delivery services as maternal satisfaction in the was low. Bench Maji Zone health department should work on improvement of the delivery services in the health centers.

\section{Declarations}

\section{Ethical approval}

Ethical clearance was received from Mizan-Tepi University. Participants were made aware about the purpose of study, and oral consents were obtained accordingly. The participants' confidentiality issues were considered.

\section{Consent to publish}

Not applicable.

\section{Availability of data and materials}

All data included in the Article.

\section{Competing interests}

Authors' declare that they have no competing interests.

\section{Funding}

No funding was received for this study.

\section{Authors' contribution}

WA, TR and AG developed the proposal, supervised the data collection and conducted the final analysis and report writing. TE drafted and critically reviewed the manuscript. All the authors approved the final manuscript. 


\section{Acknowledgments}

Our deepest gratitude goes to Mizan Aman College of Health Sciences for supporting the research by supplying all the necessary materials. Our great appreciation also goes to the data collectors and supervisors.

\section{References}

1. World Health Organization (2018) Trends in maternal mortality, Fact sheet.

2. Thomason J, Edwards K (1991) Using indicators to assess quality of hospital services in Papua New Guinea. Int J Health Plann Manage 6: 309-324.

3. Haddad S, Fournier P, Machouf N, Yatara F (1998) What does quality mean to lay people? Community perceptions of primary care services in Guinea. Soc Sci Med 47: 381-394.

4. Andaleeb SS (2001) Service quality perceptions and patient satisfaction: A study of hospitals in a developing country. Soc Sci Med 52: 1359-1370.

5. Reerink IH, Sauerborn R (1996) Quality of primary health care in developing countries: Recent experiences and future directions. Int J Qual Health Care 8: 131-139.

6. Dettrick Z, Firth S, Soto EJ (2013) Do strategies to improve quality of maternal and child health care in lower and middle income countries lead to improved outcomes? A review of the evidence. PLoS One 8: e83070.

7. Mpembeni RNM, Killewo JZ, Leshabari MT, Massawe
SN, Jahn A, et al. (2007) Use pattern of maternal health services and determinants of skilled care during delivery in Southern Tanzania: Implications for achievement of MDG-5 targets. BMC Pregnancy Childbirth 7: 29.

8. Donabedian A (1980) The definition of quality and approaches to its assessment. Ann Harbor: Health Administration Press.

9. Christiaens W, Bracke P (2007) Assessment of social psychological determinants of satisfaction with childbirth in a cross-national perspective. BMC Pregnancy Childbirth 7: 26.

10. Williams B (1994) Patient satisfaction: A valid concept. Soc Sci Med 38: 509-516.

11. Linder-Pelz S (1982) Toward a theory of patient satisfaction. Soc Sci Med 16: 577-582.

12. Tesfaye T, Worku A, Godana W, Lindtjorn B (2016) Client satisfaction with delivery care service and associated factors in the public health facilities of Gamo Gofa Zone, Southwest Ethiopia. Obstetrics and Gynecology International 2016.

13. Mekonnen E, Yalew W, Anteneh Z (2014) Women's satisfaction with childbirth care in Felege Hiwot Referral Hospital, Bahir Dar city, Northwest Ethiopia, 2014: Cross sectional study. BMC Res Notes 8: 528.

14. Bitew K, Ayichiluhm M, Yimam K (2015) Maternal satisfaction on delivery service and its associated factors among mothers who gave birth in public health facilities of Debre Markos Town, Northwest Ethiopia. Biomed Res Int 2015: 460767. 